OPEN ACCESS

Edited by:

Ming Yang,

Sichuan University, China

Reviewed by:

Fernando M. Runzer-Colmenares, Scientific University of the South, Peru

Liang-Yu Chen,

Taipei Veterans General

Hospital, Taiwan

*Correspondence:

Lydia Lera

Ilera@inta.uchile.c

tThese authors have contributed equally to this work

Specialty section:

This article was submitted to Geriatric Medicine

a section of the journal

Frontiers in Medicine

Received: 22 December 2021

Accepted: 24 January 2022

Published: 16 February 2022

Citation:

Moreno X, Lera L, Márquez C and Albala C (2022) Forecasting Healthy

Life Expectancy Among Chilean Community-Dwelling Older Adults With and Without Sarcopenia.

Front. Med. 9:841810.

doi: 10.3389/fmed.2022.841810

\section{Forecasting Healthy Life Expectancy Among Chilean Community-Dwelling Older Adults With and Without Sarcopenia}

\author{
Ximena Moreno ${ }^{1,2 \dagger}$, Lydia Lera ${ }^{1,3 *}$, Carlos Márquez ${ }^{1}$ and Cecilia Albala ${ }^{1}$ \\ ${ }^{1}$ Unidad de Nutrición Pública, Instituto de Nutrición y Tecnología de los Alimentos, Universidad de Chile, Santiago, Chile, \\ ${ }^{2}$ Facultad de Psicología, Universidad San Sebastián, Santiago, Chile, ${ }^{3}$ Latin Division, Keiser University, Fort Lauderdale, FL, \\ United States
}

Background: Sarcopenia is an important risk factor for disability and dependency at old age. The prevalence of sarcopenia among the Chilean older population is high.

Objective: To estimate life expectancy, healthy life expectancy and unhealthy life expectancy among sarcopenic and non-sarcopenic older adults from Santiago, Chile.

Methods: A sample of 1,897 community-dwelling older adults aged 60 years or more, living in Santiago, was observed between 5-15 years. Disability was defined as the unhealthy state, assessed through self-reported difficulties in activities of daily living. Sarcopenia was determined via HTSMayor software. Total and marginal life expectancies were estimated using the Interpolated Markov Chain method "IMaCh".

Results: At 60 years, estimated life expectancy for sarcopenic and non-sarcopenic older adults was similar (22.7 and 22.5 years, respectively). The proportion of years to be lived with disability was three times greater in sarcopenic adults, compared to non-sarcopenic people. This difference was observed up to 80 years. Non-sarcopenic women had a higher proportion of years to be lived with disabilities compared to non-sarcopenic men of the same age, but this proportion was higher among sarcopenic men, compared to sarcopenic women until 70 years of age.

Discussion: People with sarcopenia expect to live a higher proportion of years with disabilities. Sarcopenic men until 70 years expected to live a higher proportion of years with disability, compared to sarcopenic women. Monitoring sarcopenia among older people may help to identify individuals with higher risk of disability onset. Future research should focus on disentangling the mechanisms explaining sex differences.

Keywords: disability-free life expectancy, life expectancy, sarcopenia, gender, longitudinal studies

\section{BACKGROUND}

Since 2016, sarcopenia has been recognized as a condition with its own code (M62.84) in the International Classification of Disease, Tenth Revision, Clinical Modification (ICD-10CM) (1). Sarcopenia is defined as a progressive and generalized skeletal muscle disorder, characterized by loss of muscle mass, strength and function, associated with age and with an increased risk 
of falls, fractures, morbidity, disability, mortality, and poor quality of life $(2,3)$. There are also economic costs for healthcare systems, individuals and families, associated with sarcopenia, due to the increased risk of hospitalization and higher costs during hospital stay, compared to people of the same age without sarcopenia (4).

Worldwide prevalence of sarcopenia is high. A recent review concluded that different definitions resulted in wide variation of estimations, and according to studies that employed the definition of the European Working Group on Sarcopenia in Older People (EWGSOP) (5), considering low muscle mass and low muscle strength or low physical performance, the average prevalence was $9.9 \%$ and increased with increasing age, reaching $19.4 \%$ in the oldest old (6). In Chile, sarcopenia prevalence estimated with the EWGSOP algorithm is $19.1 \%$, similar for men and women, and it is associated with age (7).

In Chile, the population aging is advanced, with the highest life expectancy (LE) at birth (80 years) of South America, along with French Guiana (8). It is important to determine if those years are lived in good health or if the additional years of life result in an expansion of morbidity among the older population (9). Considering that sarcopenia is a highly prevalent condition among older adults, and that its is associated with disability (10), it is necessary to determine the impact of sarcopenia on health expectancies.

Health expectancies integrate health status to the LE indicator, providing information with respect to the total number of years expected to be lived at a certain age, and the number of years expected to be lived in a certain health status, such as free of disability (9). Estimations of health expectancies in Chile are scarce. Previous Chilean studies reported that women at 60 years expected to live a higher proportion of years with disabilities, compared to men of the same age (11-13).

The aim of this study was to estimate LE, healthy life expectancy (HLE) and unhealthy life expectancy (ULE) among sarcopenic and non-sarcopenic older adults from Santiago, Chile.

\section{METHODS}

This is a dynamic cohort study. The sample included 1,897 people aged 60 years and older, living in the community in Santiago, Chile, who were originally recruited to the Alexandros (14) and HTS Mayor (15) projects, aimed to study disability associated with obesity and sarcopenia in Chilean older people. The Alexandros sample $(N=2,311)$ was recruited between 2003 and 2008, and the HTS Mayor sample $(N=169)$, in 2012. Baseline information was collected between 2003-2012. People who died in the following 6 months from baseline (1.5\%), and those who had missing data in the outcome variables (3.8\%) were excluded from the analyses. Sixty-eight people (2.7\%) rejected to take part in this study. From a total of 2,281 people who were eligible and accepted to take part in this study, $384(16.8 \%)$ were lost to follow-up (Supplementary Material 1). One thousand eight hundred ninety-seven participants were followed-up between 5-15 years (interquartile range 5.17 years), until 2017.

Data were collected via face-to-face interviews, carried out by trained interviewers at the Institute of Nutrition and Food Technology. The interviews included a structured questionnaire to gather sociodemographic information and self-reported health problems, including chronic diseases and functional status. The 5 item Geriatric Depression Scale (GDS-5) (16) was used to determine depressive symptoms. Cognitive status was assessed via the Mini-Mental State Examination (MMSE) (17) and the Functional Activities Questionnaire (FAQ) (18). Anthropometric measurements included weight, knee height, waist, hip, and calf circumference. Handgrip strength was measured in the dominant hand, with calibrated dynamometers, following the Southampton protocol. Mobility was assessed with questions about the ability to walk several blocks, climbing stairs, pushing or pulling heavy objects, lifting or carrying weights over ten $5 \mathrm{~kg}$, and picking up a coin from a table. The details of the operationalization of sarcopenia are described below.

Functional status was determined according to the criteria proposed by Albala et al. (19) for the Chilean older population, considering limitation in at least one activity of daily living (ADL), or in two instrumental activities of daily living (IADL), or in three advanced activities of daily living (AADL), or a score of $\mathrm{MMSE}<13$ and PFAQ $>5$.

Sarcopenia was defined as an adapted version of the diagnostic algorithm of the European Working group on Sarcopenia in Older People (EWGSOP1) in 2010 (5), considering low physical performance, low muscle strength, and/or low muscle mass. Participants with sarcopenia were identified by means of HTSMayor software (14). A prediction model for the Chilean population (18) was employed to estimate appendicular skeletal muscle mass (ASM):

ASM $(\mathrm{kg})=0.107$ (weight) +0.251 (knee-height $)+$ 0.197 (calf-circumference) +0.047 (dynamometry) -0.034 (hip-circumference) + 3.4178 (male) - 0.020 (age) - 7.646;

Coefficient of determination $=0.89$;

Standard Error of the Estimation $=1.346 \mathrm{~kg}$.

Cut-off points of the skeletal muscle mass index (SMI = ASM/height ${ }^{2}$ ) for the Chilean population were obtained from this prediction model, resulting in $7.45 \mathrm{~kg} / \mathrm{m}^{2}$ for men, and 5.88 $\mathrm{kg} / \mathrm{m}^{2}$ for women (20). Muscle strength was assessed considering the best two scores obtained with a handgrip dynamometer, using the dominant hand. Cut-off points previously estimated for the Chilean population $(21,22)$ were employed. A combination of two physical performance tests was used to assess this dimension, since not all participants had the three meters $(3 \mathrm{~m})$ walking speed register. The tests used were $3 \mathrm{~m}$ walking speed and timed up and go (TUG) speed, in this order (23).

Mortality data were confirmed via death certificates obtained from the National Civil Registry until July 30, 2017. Vital status of all participants was known by the end of follow-up.

Descriptive analyses were carried out with Stata 15 (StataCorp.2015. Stata Statistical Software, Release 14. College Station, TX, StataCorp LP). To estimate life expectancies and disability-free life expectancies, multistate methods were employed. Three states were considered-healthy, disabled, and 
TABLE 1 | Baseline characteristics of the sample.

\begin{tabular}{|c|c|c|c|c|}
\hline Variable & $\begin{array}{c}\text { Total }(n=1,897) \\
\%\end{array}$ & $\begin{array}{c}\text { Men }(n=612) \\
\%\end{array}$ & $\begin{array}{c}\text { Women }(n=1,285) \\
\%\end{array}$ & $P$-value \\
\hline Age $\left(\right.$ years) ${ }^{*}$ & $69.2 \pm 6.8$ & $69.3 \pm 6.4$ & $69.2 \pm 7.0$ & 0.7651 \\
\hline $60-69.9$ & 70.0 & 68.0 & 71.0 & \\
\hline $70-79.9$ & 20.5 & 23.7 & 18.9 & \\
\hline Living alone & 10.0 & 8.9 & 10.5 & 0.290 \\
\hline Functional limitation & 16.6 & 11.4 & 19.1 & $<0.001$ \\
\hline Multimorbidity ( $\geq 2 \mathrm{CD}$ ) & 47.4 & 42.8 & 49.6 & $<0.001$ \\
\hline Depression (GDS-5) & 30.9 & 26.3 & 33.0 & 0.0031 \\
\hline$B M l^{\star}$ & $28.6 \pm 5.0$ & $27.5 \pm 4.4$ & $29.1 \pm 5.2$ & $<0.001$ \\
\hline Overweight & 43.5 & 47.1 & 41.8 & \\
\hline Obese & 33.4 & 24.7 & 37.6 & \\
\hline Sarcopenia & 22.4 & 22.1 & 22.6 & 0.804 \\
\hline Falls & 32.6 & 27.8 & 34.8 & 0.003 \\
\hline ADL limitation $\geq 1$ & 11.9 & 11.3 & 12.2 & 0.553 \\
\hline IADL limitation $\geq 1$ & 26.8 & 31.2 & 24.8 & 0.003 \\
\hline MMSE & 6.8 & 6.4 & 7.0 & 0.649 \\
\hline
\end{tabular}

*Mean and standard deviation.

TABLE 2 | Total life expectancy, healthy life expectancy and unhealthy life expectancy, among sarcopenic and non-sarcopenic Chilean older men and women.

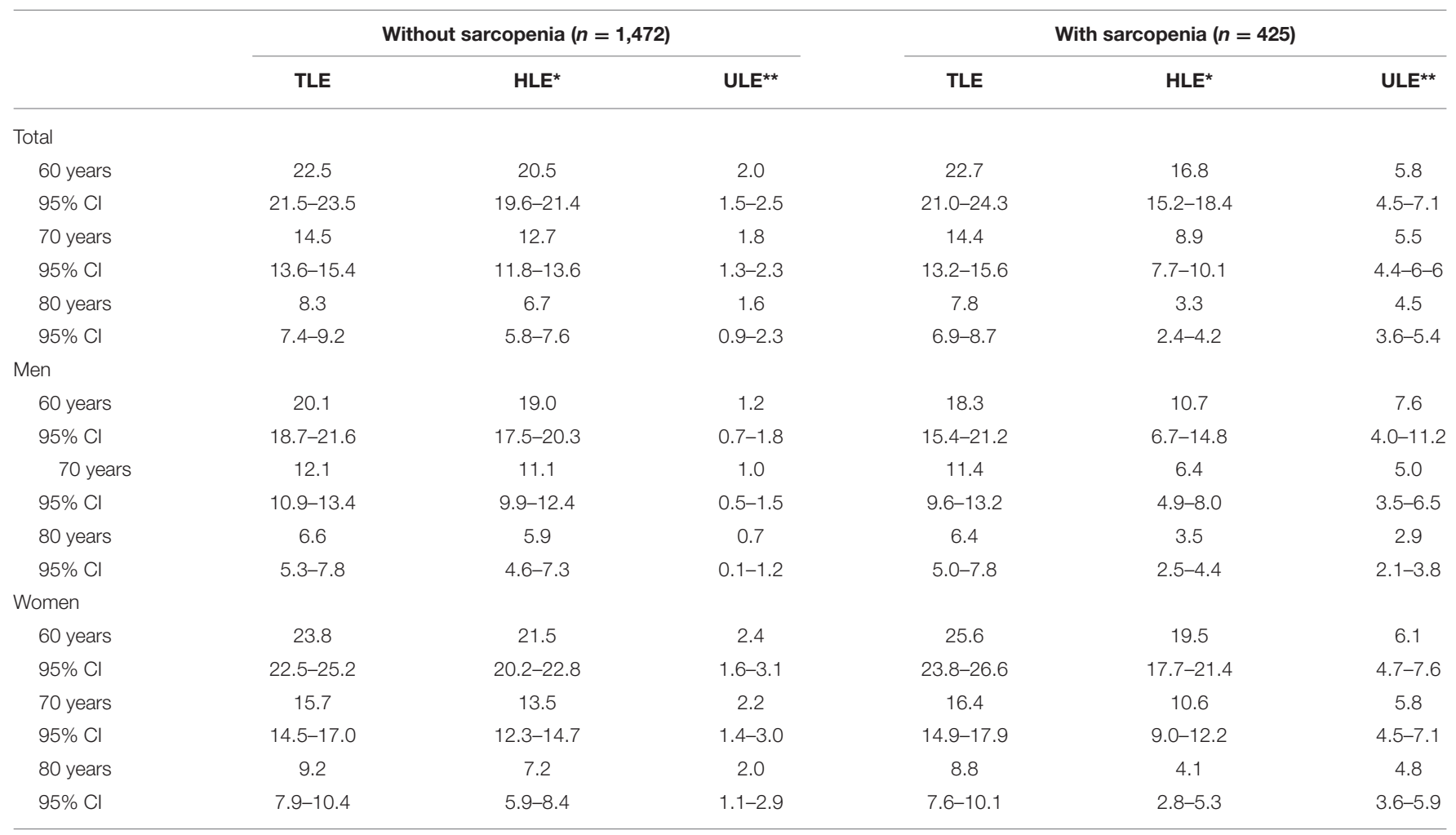

"Healthy life expectancy (without disability). "Unhealthy life expectancy (with disability). 

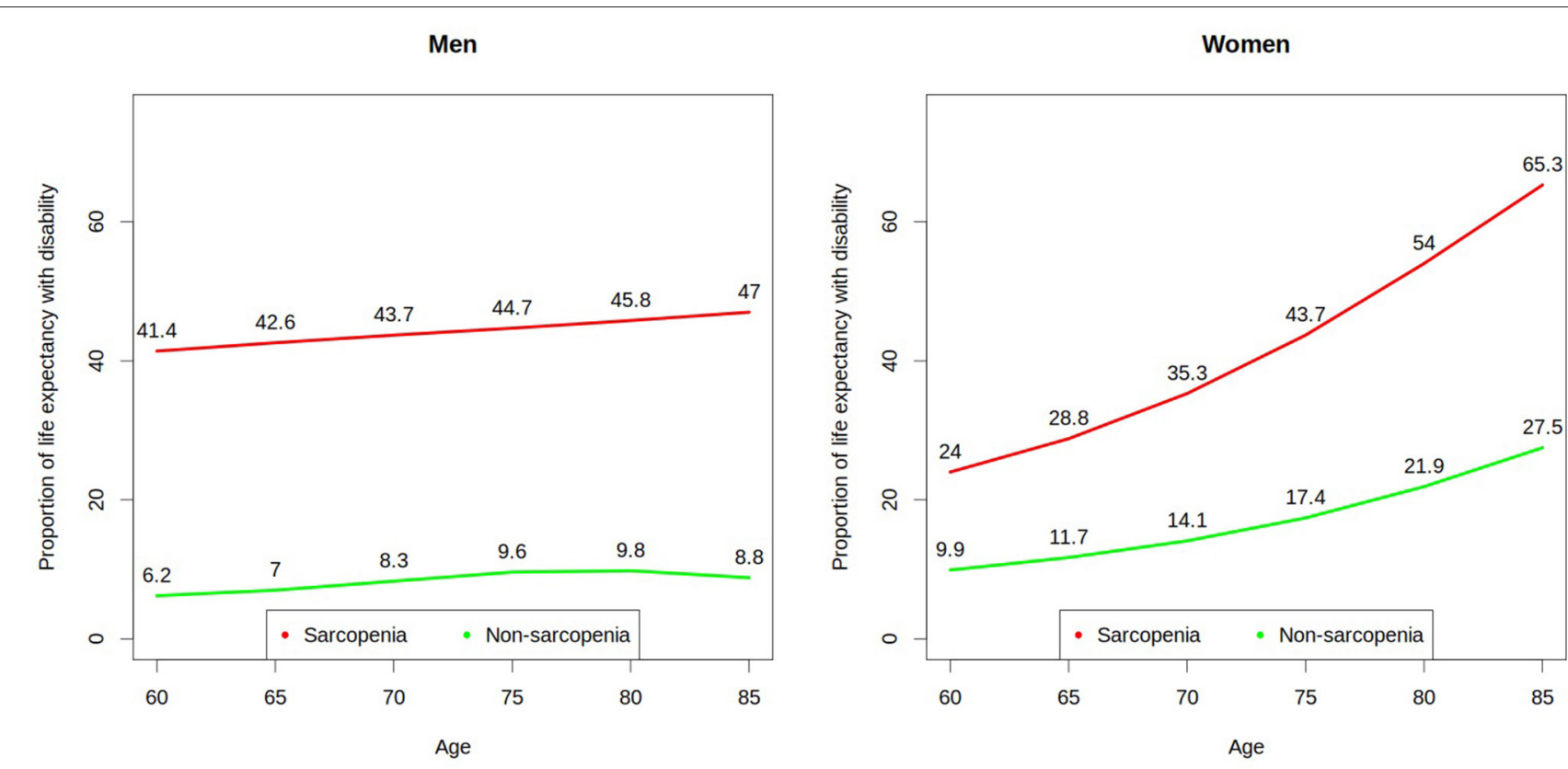

FIGURE 1 | Proportion of life expectancy to be lived with disability by Chilean older men and women with and without baseline sarcopenia.

dead-with five possible transitions: healthy-healthy, healthydisabled, disabled-healthy, healthy-dead, disabled-dead. The Interpolated Markov Chain (IMaCh) software was employed for the calculations $(24,25)$. Estimations were expressed as number of years and percentages, and $95 \%$ confidence intervals were calculated.

Cox proportional hazards models were used to estimate the association between sarcopenia and the incidence of functional limitation, including sociodemographic variables, body mass index, multimorbidity (defined as two or more self-reported chronic diseases, including high blood pressure, diabetes, coronary heart disease, stroke, chronic obstructive pulmonary disease, cancer, and arthritis), depressive symptoms, and falls. Self-reported depression was not included in this variable, due to the underdiagnosis of depression by health care providers in Chile (26). No violations of the proportional hazards' assumption were detected. Since falls and depression have been previously reported as risk factors of functional limitation (2730 ), interaction terms between sarcopenia and each of these variables were tested.

Study protocols and consent forms were approved by the ethics committee of the Institute of Nutrition and Food Technology. All participants gave signed informed consent.

\section{RESULTS}

As observed in Table 1, the sample had a higher proportion of women $(67.7 \%)$, and the mean age was 69.2 years $(S D=6.8)$. Baseline prevalence of sarcopenia was $22.4 \%$, with no difference between men and women $(p=0.8)$. Functional limitation had a prevalence of $16.6 \%($ men $=11.4 \%$, women $=19.1 \%)$.
Participants were followed-up for a median of 5.8 years, and a total of 6,358.6 person years. During the follow-up, 105 new cases of functional decline were observed, 127 people with baseline functional limitation had recovered and 492 deaths occurred.

Table 2 shows that LE of sarcopenic and non-sarcopenic older adults at 60 years was 22.7 and 22.5 years, respectively. There were no differences in LE between both groups, but at every age, non-sarcopenic older adults had more healthy years and less ULE. Total LE was significantly longer for women than men at all ages, with the exception of participants with sarcopenia at 80 years. No significant difference was observed in total LE among sarcopenic and non-sarcopenic men. Among women, there were no differences in total LE between groups, but sarcopenic women expected to live more years with disabilities, compared to nonsarcopenic women, and had a shorter healthy life expectancy at age 70 and 80 .

As observed in Figure 1, sarcopenic men had a higher proportion of expected ULE, compared to non-sarcopenic men, with a proportion of ULE 6.6 times higher at 60 years, 5.3 times higher at 70 and 4.7 times higher at 80 years. The proportion of ULE among sarcopenic women was 2.4 times higher at age 60, 2.5 times higher at age 70 and 4.0 times higher at age 80, compared to non-sarcopenic women. Sarcopenic men at 60 and 70 years of age had a higher proportion of expected ULE, compared to sarcopenic women of the same age, with a difference of 17.4 and 8.4 percent points, at the respective age. On the contrary, among non-sarcopenic people at ages 69,70 , and 80, a higher proportion of LE was expected to be lived with disabilities among women, compared to men $(3.7,5.8$, and 12.1 percent point, respectively).

Cox proportional hazards models showed that sarcopenia and age were the only variables associated with the incidence of 
TABLE 3 | Hazard ratio of functional limitation among Chilean older people from the Alexandros and HTS Mayor studies, $2003-2017$.

\begin{tabular}{|c|c|c|c|c|}
\hline & $\begin{array}{c}\text { Model } 1 \\
\text { HR }(95 \% \mathrm{Cl})\end{array}$ & $\begin{array}{c}\text { Model } 2 \\
\text { HR }(95 \% \mathrm{Cl})\end{array}$ & $\begin{array}{c}\text { Model } 3 \\
\text { HR }(95 \% \mathrm{Cl})\end{array}$ & $\begin{array}{c}\text { Model } 4 \\
\text { HR }(95 \% \mathrm{Cl})\end{array}$ \\
\hline Sarcopenia & $3.40(2.11-5.49)$ & 3.65 (2.02-6.62) & 3.69 (1.99-6.86) & $3.85(2.05-7.22)$ \\
\hline Age (years) & 1.07 (1.03-1.11) & 1.07 (1.03-1.11) & 1.07 (1.03-1.11) & $1.07(1.03-1.11)$ \\
\hline Women & $0.80(0.49-1.31)$ & $0.79(0.49-1.30)$ & $0.88(0.52-1.48)$ & $0.82(0.48-1.40)$ \\
\hline \multicolumn{5}{|l|}{ Nutritional state } \\
\hline $\mathrm{BMI}<20$ & & 1.06 (0.39-2.86) & $0.80(0.25-2.52)$ & $0.78(0.25-2.47)$ \\
\hline BMl: 25-29.9 & & $0.94(0.54-1.64)$ & $0.97(0.54-1.74)$ & $0.97(0.54-1.74)$ \\
\hline $\mathrm{BMl}: \geq 30$ & & 1.17 (0.54-2.53) & $1.22(0.55-2.70)$ & $1.22(0.55-2.72)$ \\
\hline Multimorbidity* & & & $0.99(0.61-1.61)$ & $0.98(0.60-1.60)$ \\
\hline Depression** & & & $1.10(0.66-1.85)$ & $1.04(0.61-1.75)$ \\
\hline Falls & & & & $1.43(0.87-2.37)$ \\
\hline
\end{tabular}

${ }^{*} \geq 2$ chronic diseases; ${ }^{*}$ GDS -5 .

functional limitation (Table 3). Interaction terms of sarcopenia with falls and with depression were not significant.

\section{DISCUSSION}

Our study found no difference in LE between sarcopenic and non-sarcopenic older people, but more ULE among the former. In absolute terms, at 60 years of age, sarcopenic men expected to live more years with disability, compared to non-sarcopenic men and women with or without sarcopenia. From 70 years, sarcopenic women expected to live more years with disability, compared to the other groups. With respect to the proportion of ULE, sarcopenic men expected to live a higher proportion of LE with disabilities, up to the age of 70 years.

According to our results, baseline sarcopenia had a differential impact on HLE and ULE of men and women. Sarcopenic men had a shorter HLE and more ULE, compared to sarcopenic women. This suggests that sarcopenia could be associated with a higher and earlier onset of disability among older men. A Brazilian study found that sarcopenia was associated with osteoporosis among older men, but not women (31). Among a Japanese sample without baseline restrictions in $\mathrm{ADL}$, almost twice as much sarcopenic men (38.8\%) as sarcopenic women (18.8\%) developed restrictions in ADL (32).

A previous study found that Chilean older women had a higher proportion of ULE, compared to men of the same age (10). However, the results of the present study show the importance of considering baseline sarcopenia to describe disability trajectories of older men and women. Women with sarcopenia had a higher proportion of ULE, compared to nonsarcopenic women. Sarcopenic older men, for their part, expected to live a greater proportion of their total LE with disabilities, compared not only to non-sarcopenic men, but to sarcopenic women as well.

Genetic, nutritional, physical activity and age-related factors are associated with the onset of sarcopenia (33). Two systematic reviews have concluded that physical activity is a protective factor against sarcopenia in men and women $(34,35)$. Nevertheless, some studies suggest that the effect of physical activity on sarcopenia onset and progression differs between sexes $(36,37)$. Rivera et al. (38) found that age and physical activity were related with muscle volume and performance in men, but not in women. According to those results, sedentarism during the life-course resulted in loss of muscular mass among men, with a negative impact on function. In the case of older women, it was observed that muscular performance and functionality was preserved despite the sarcopenic process. The role of physical activity on different trajectories of disability among sarcopenic older men and women should be further studied. Also, other potential factors associated with these differences, which act as protective factors for women or negatively affect men, should be elucidated.

This study has some limitations that should be considered. ASM was estimated by an anthropometric equation instead of dual-energy X-ray absorptiometry (DXA), which is considered the gold standard to measure body composition (39). However, this equation and DXA had a high concordance correlation coefficient (0.94) in a previous Chilean study (40). On the other hand, considering the technical difficulties to assess muscle mass and quality, and the ability of muscle strength and physical performance to predict adverse outcomes, these latter measures of physical performance are primarily used (2, $4)$. The sample size affected the precision of our estimations, particularly in stratified analyses and for older ages. Nevertheless, we found significant differences between groups. The participants of the study were recruited among older people living in Santiago. Hence, our results are not representative at a national level. Also, the sample did not include people living in rural areas. According to previous research, Chilean older people living in rural areas have worse health status and higher levels of disability (41). Lastly, attrition bias cannot be ruled out, which could have affected out estimations, in case the distribution of sarcopenia or disability incidence varied between the participants in our study and those lost to follow-up. A higher or lower incidence of disability among men or women with or without sarcopenia who were not followedup, could result in over or underestimation of years to be 
lived with disability, in one or several of the groups. This limitation should be taken into account when interpreting the results.

In conclusion, our results stress the importance of monitoring sarcopenia among older adults, to identify those individuals at a greater risk of disability onset. Sex differences observed in disability trajectories among sarcopenic older people should be disentangled by future research.

\section{DATA AVAILABILITY STATEMENT}

The raw data supporting the conclusions of this article will be made available by the authors, without undue reservation.

\section{ETHICS STATEMENT}

The studies involving human participants were reviewed and approved by Ethics Committee of the Institute of Nutrition and Food Technology. The patients/participants provided their written informed consent to participate in this study.

\section{REFERENCES}

1. Cao L, Morley JE. Sarcopenia is recognized as an independent condition by an international classification of disease, tenth revision, clinical modification (ICD-10-CM) code. J Am Med Dir Assoc. (2016) 17:675-7. doi: 10.1016/j.jamda.2016.06.001

2. Cruz-Jentoft AJ, Bahat G, Bauer J, Boirie Y, Bruyère $O$, Cederholm T, et al. Sarcopenia: revised European consensus on definition and diagnosis. Age Ageing. (2019) 48:601. doi: 10.1093/ageing/afz046

3. Landi F, Calvani R, Cesari M, Tosato M, Martone AM, Ortolani E, et al. Sarcopenia: an overview on current definitions, diagnosis and treatment. Curr Protein Pept Sci. (2018) 19:633-8. doi: 10.2174/1389203718666170607113459

4. Cruz-Jentoft AJ, Sayer AA. Sarcopenia. Lancet. (2019) 393:263646. doi: 10.1016/S0140-6736(19)31138-9

5. Cruz-Jentoft AJ, Baeyens JP, Bauer JM, Boirie Y, Cederholm T, Landi F, et al. Sarcopenia: European consensus on definition and diagnosis: report of the European Working Group on Sarcopenia in older people. Age Ageing. (2010) 39:412-23. doi: 10.1093/ageing/afq034

6. Mayhew AJ, Amog K, Phillips S, Parise G, McNicholas PD, de Souza RJ, et al. The prevalence of sarcopenia in community-dwelling older adults, an exploration of differences between studies and within definitions: a systematic review and meta-analyses. Age Ageing. (2019) 48:48-56. doi: 10.1093/ageing/afy106

7. Lera L, Albala C, Sánchez H, Angel B, Hormazabal MJ, Márquez C, et al. Prevalence of sarcopenia in community-dwelling chilean elders according to an adapted version of the European Working Group on Sarcopenia in Older People (EWGSOP) criteria. J Frailty Aging. (2017) 6:127. doi: 10.14283/jfa.2016.117

8. United Nations. Department of Economic and Social Affairs, Population Division (2019). World Population Prospects 2019: Data Booket. ST/ESA/SER.A/424 (2019).

9. Saito Y, Robine J-M, Crimmins EM. The methods and materials of health expectancy. Stat J IAOS. (2014) 30:209-23. doi: 10.3233/SJI-140840

10. Beaudart C, Zaaria M, Pasleau F, Reginster JY, Bruyère O. Health outcomes of sarcopenia: a systematic review and meta-analysis. PLoS One. (2017) 12:e0169548. doi: 10.1371/journal.pone.0169548

11. Moreno X, Albala C, Lera L, Leyton B, Angel B, Sánchez H. Gender, nutritional status and disability-free life expectancy among older people in Santiago, Chile. PLoS One. (2018) 13:e0194074. doi: 10.1371/journal.pone.0194074

\section{AUTHOR CONTRIBUTIONS}

LL and CA designed the primary studies. CM coordinated the data collection. LL and XM designed the secondary analyses that are reported here and wrote the draft of the manuscript. LL performed the statistical analyses. All authors revised, commented, and approved the final version of the manuscript.

\section{FUNDING}

This research was supported by the Chilean National Fund for Scientific and Technological Development (Fondecyt grant 1130947 and Fondef grant 15I10053). The funders had no role in study design, data collection and analysis, decision to publish, or preparation of the manuscript.

\section{SUPPLEMENTARY MATERIAL}

The Supplementary Material for this article can be found online at: https://www.frontiersin.org/articles/10.3389/fmed. 2022.841810/full\#supplementary-material

12. Moreno X, Lera L, Albala C. Disability-free life expectancy and life expectancy in good self-rated health in Chile: gender differences and compression of morbidity between 2009 and 2016. PLoS One. (2020) 15:e0232445. doi: 10.1371/journal.pone.0232445

13. Moreno X, Lera L, Moreno F, Albala C. Socioeconomic inequalities in life expectancy and disability-free life expectancy among Chilean older adults: evidence from a longitudinal study. BMC Geriatr. (2021) 21:176. doi: 10.1186/s12877-021-02126-9

14. Albala C, Sánchez H, Lera L, Angel B, Cea X. [Socioeconomic inequalities in active life expectancy and disability related to obesity among older people]. Rev Med Chil. (2011) 139:1276-85.

15. Lera L, Angel B, Márquez C, Saguez R, Albala C. Software for the diagnosis of sarcopenia in community-dwelling older adults: design and validation study. JMIR Med Informatics. (2020) 8:e13657. doi: 10.2196/13657

16. Hoyl MT, Alessi CA, Harker JO, Josephson KR, Pietruszka FM, Koelfgen $M$, et al. Development and testing of a five-item version of the Geriatric Depression Scale. J Am Geriatr Soc. (1999) 47:873-8. doi: 10.1111/j.1532-5415.1999.tb03848.x

17. Folstein M, Folstein S, McHugh P. Mini-mental state. a practical method for grading the cognitive state of patients for the clinician. J Psychiatr Res. (1975) 12:189-98. doi: 10.1016/0022-3956(75)90026-6

18. Pfeffer R, Kurosaki T, Harrah C, Chance J, Filos S. Measurement of functional activities in older adults in the community. J Gerontol. (1982) 37:3239. doi: 10.1093/geronj/37.3.323

19. Albala C, Lera L, García C, El A, Garcia C, Arroyo P, et al. Searching a common definition for functional limitation in Latin America. Gerontologist. (2004) 44:550.

20. Lera L, Ángel B, Sánchez H, Picrin Y, Hormazabal MJ, Quiero A, et al. [Validation of cut points of skeletal muscle mass index for identifying sarcopenia in Chilean older people]. Nutr Hosp. (2015) 31:1187-97. doi: 10.3305/nh.2015.31.3.8054

21. Arroyo P, Lera L, Sánchez H, Bunout D, Santos JL, Albala C. [Anthropometry, body composition and functional limitations in the elderly]. Rev Med Chil. (2007) 135:846-54. doi: 10.4067/S0034-98872007000700 004

22. Lera L, Albala C, Leyton B, Márquez C, Angel B, Saguez R, et al. Reference values of hand-grip dynamometry and the relationship between low trength and mortality in older Chileans. Clin Interv Aging. (2018) 13:31724. doi: $10.2147 /$ CIA.S152946 
23. Lera L, Angel B, Marquez C, Saguez R, Albala C. Besides Sarcopenia, presarcopenia also predicts all-cause mortality in older chileans. Clin Interv Aging. (2021) 16:611-9. doi: 10.2147/CIA.S289769

24. Molla MT, Madans JH. Estimating healthy life expectancies using longitudinal survey data: methods and techniques in population health measures. National center for health statistics. Vital Health Stat. (2008) 2.

25. Lièvre $A$, Brouard $\mathrm{N}$, Heathcote C. The estimation of health expectancies from cross-longitudinal surveys. Math Popul Stud. (2003) 10:211-48. doi: 10.1080/713644739

26. Aravena JM, Saguez R, Lera L, Moya MO, Albala C. Factors related to depressive symptoms and self-reported diagnosis of depression in community-dwelling older Chileans: a national cross-sectional analysis. Int J Geriatr Psychiatry. (2020) 35:749-58. doi: 10.1002/gps.5293

27. Hajek A, Brettschneider C, Posselt T, Lange C, Mamone S, Wiese B, et al. Predictors of frailty in old age - results of a longitudinal study. J Nutr Health Aging. (2016) 20:952-7. doi: 10.1007/s12603-015-0634-5

28. Hajek A, König $\mathrm{H}-\mathrm{H}$. Longitudinal predictors of functional impairment in older adults in Europe-evidence from the survey of health, ageing and retirement in Europe. PLoS One. (2016) 11:e0146967. doi: 10.1371/journal.pone.0146967

29. Jefferis BJ, Iliffe S, Kendrick D, Kerse N, Trost S, Lennon LT, et al. How are falls and fear of falling associated with objectively measured physical activity in a cohort of community-dwelling older men? BMC Geriatr. (2014) 14:114. doi: 10.1186/1471-2318-14-114

30. Tinetti ME, Williams CS. The effect of falls and fall injuries on functioning in community-dwelling older persons. J Gerontol A Biol Sci Med Sci. (1998) 53:M112-9. doi: 10.1093/gerona/53A.2.M112

31. Frisoli A, Martin FG, Carvalho AC de C, Borges J, Paes AT, Ingham SJM. Sex effects on the association between sarcopenia EWGSOP and osteoporosis in outpatient older adults: data from the SARCOS study. Arch Endocrinol Metab. (2018) 62:615-22. doi: 10.20945/2359-3997000000087

32. Tanimoto Y, Watanabe M, Sun W, Sugiura Y, Tsuda Y, Kimura M, et al. Association between sarcopenia and higher-level functional capacity in daily living in community-dwelling elderly subjects in Japan. Arch Gerontol Geriatr. (2012) 55:e9-13. doi: 10.1016/j.archger.2012.06.015

33. Fielding RA, Vellas B, Evans WJ, Bhasin S, Morley JE, Newman AB, et al. Sarcopenia: an undiagnosed condition in older adults. current consensus definition: prevalence, etiology, and consequences. International Working Group on Sarcopenia. J Am Med Dir Assoc. (2011) 12:24956. doi: 10.1016/j.jamda.2011.01.003

34. Beaudart C, Reginster J, Slomian J, Buckinx F, Locquet $M$, Bruyère O. Prevalence of sarcopenia : the impact of different diagnostic cut-off limits. J Musculoskelet Neuronal Interact. (2014) 14:425-31. doi: 10.1016/S1878-7649(14)70510-8
35. Shaw SC, Dennison EM, Cooper C. Epidemiology of sarcopenia: determinants throughout the lifecourse. Calcif Tissue Int. (2017) 101:229-47. doi: 10.1007/s00223-017-0277-0

36. Iannuzzi-Sucich M, Prestwood KM, Kenny AM. Prevalence of sarcopenia and predictors of skeletal muscle mass in healthy, older men and women. J Gerontol A Biol Sci Med Sci. (2002) 57:M772-7. doi: 10.1093/gerona/57.12.M772

37. Tay L, Ding YY, Leung BP, Ismail NH, Yeo A, Yew S, et al. Sex-specific differences in risk factors for sarcopenia amongst community-dwelling older adults. Age. (2015) 37:121. doi: 10.1007/s11357-015-9860-3

38. Rivera J de J, Fonseca-Sanchez MA, Rodriguez P, Garcia JM, Palma I, Aristi G, et al. Physical activity protects men but not women for sarcopenia development. Gerontol Geriatr Med. (2016) 2:2333721416667879. doi: 10.1177/2333721416667879

39. Guglielmi G, Ponti F, Agostini M, Amadori M, Battista G, Bazzocchi A. The role of DXA in sarcopenia. Aging Clin Exp Res. (2016) 28:104760. doi: 10.1007/s40520-016-0589-3

40. Lera L, Albala C, Ángel B, Sánchez H, Picrin Y, Hormazabal M, et al. [Anthropometric model for the prediction of appendicular skeletal muscle mass in Chilean older adults]. Nutr Hosp. (2014) 29:611-7. doi: 10.3305/nh.2014.29.3.7062

41. SENAMA. Las personas mayores en Chile. Situación, avances y desafíos del envejecimiento y la vejez. Servicio Nacional del Aduto Mayor (SENAMA) 2010. Estudio Nacional de la Dependencia en las Personas Mayores. Chile: Gráfica Puerto Madero (2010).

Conflict of Interest: The authors declare that the research was conducted in the absence of any commercial or financial relationships that could be construed as a potential conflict of interest.

Publisher's Note: All claims expressed in this article are solely those of the authors and do not necessarily represent those of their affiliated organizations, or those of the publisher, the editors and the reviewers. Any product that may be evaluated in this article, or claim that may be made by its manufacturer, is not guaranteed or endorsed by the publisher.

Copyright (C) 2022 Moreno, Lera, Márquez and Albala. This is an open-access article distributed under the terms of the Creative Commons Attribution License (CC BY). The use, distribution or reproduction in other forums is permitted, provided the original author(s) and the copyright owner(s) are credited and that the original publication in this journal is cited, in accordance with accepted academic practice. No use, distribution or reproduction is permitted which does not comply with these terms. 